\title{
Síndrome de Burnout em professores universitários: revisão integrativa da literatura
}

\author{
Burnout syndrome in university professors: integrative literature review
}

Síndrome de Burnout en profesores universitarios: revisión bibliográfica integradora

Maricélia Tavares Borges Oliveira ${ }^{1 *}$, Antonio Marques Martins ${ }^{1}$, Monielle Guerra Justino ${ }^{1}$, José Humberto Gomes Oliveira², Simonetta Pisano ${ }^{3}$, Clelson Gomes da Silva Pessoa ${ }^{4}$, Rayane Cristina Rodrigues Pessoa Gomes ${ }^{1}$, Valdirene Cássia da Silva ${ }^{5,6}$, Ana Kleiber Pessoa Borges ${ }^{7}$.

\section{RESUMO}

Objetivo: Investigar a temática da Síndrome de Burnout em professores universitários, em dissertações e teses brasileiras. Métodos: Trata-se de uma revisão integrativa, realizada com suporte em resumos disponíveis na base de dados do Portal de Periódicos da Coordenação de Aperfeiçoamento de Pessoal de Nível Superior (Capes) dissertações e teses, que utilizou como assunto para a busca Síndrome de Burnout, docentes, universidades, estresse ocupacional na qual foram encontradas 37 produções, no período de 2008 a 2018. Resultados: A pesquisa resultou em 37 estudos relacionados à Síndrome de Burnout em professores universitários, dos quais 21 são dissertações de mestrado acadêmico, 10 são teses de doutorado e 06 são dissertações de mestrado profissional. As tabelas mostram sequência das produções científicas da pós-graduação brasileira encontradas no Portal CAPES teses, referente ao tema abordado. Considerações finais: Constatou-se crescimento do número de produções sobre a temática, sendo a área da Administração a mais sensibilizada pelo tema. Em relação à implementação educativa na prevenção desta patologia, observaram-se poucos estudos com este objetivo. Concluiu-se, então, a necessidade de elaborar pesquisas que valorizem a Síndrome de Burnout como foco de intervenção que visem à melhoria da qualidade do trabalho de docentes e demais profissões.

Palavras-chave: Burnout, Docentes, Universidades, Estresse ocupacional.

\section{ABSTRACT}

Objective: To investigate the theme of Burnout Syndrome in university professors, in Brazilian dissertations and theses. Methods: This Bibliografic Study was conducted with the support of summaries avalaible on the Portal de Periódicos da Coordenação de Aperfeiçoamento de Pessoal de Nível Superior (Capes) thesis, dissertations database.The search strategy was based on the descriptors: Burn Out Syndrom Professors, Universities, Occupational Stress, fore such, 37 studies were selected concerning the time period from 2008 to 2018. Results: The research resulted in 37 studies related to Burnout Syndrome in university professors, of which 21 are academic master's dissertations, 10 are theses of doctorate and 06 are Professional master's theses. The tables show the sequence of scientific productions of Brazilian post graduate studies found in the CAPES Portal theses, referring to the topic addressed. Final considerations: It was observed the increased production on the Burn Out subject, being mainly investigated by the Business Administration field. Concerning, educational implementation emerged that only a small number of studies fucuses on the prevention of this syndrome. Thus, the necessity to alaborate searchs on Burn Out Syndrome concentrating on the intervention criteria, aiming to enhance professors and other professionals work quality.

Keywords: Burnout, Faculty, Universities, Occupational stress.

1 Universidade Federal do Tocantins. Palmas - TO. *E-mail: mariceliatbo@gmail.com

${ }^{2}$ Faculdade Cidade Verde, Secretaria Municipal de Saúde de Imperatriz. Imperatriz - MA.

${ }^{3}$ Universidade Federal do Paraná. Curitiba - PR.

${ }^{4}$ Faculdade do Bico do Papagaio (FABIC). Augustinópolis - TO.

${ }^{5}$ Universidade Luterana de Palmas (CEULP/ULBRA). Palmas - TO.

${ }^{6}$ Faculdade Católica do Tocantins (FACTO). Palmas - TO.

7 Universidade Federal do Tocantins (UFT). Palmas - TO. 


\section{RESUMEN}

Objetivo: Investigar el tema del Síndrome de Burnout en profesores universitarios, en disertaciones y tesis brasileñas. Métodos: Esta es una revisión integradora, realizada conela poyo de los resúmenes disponibles en la base de datos del Portal de Publicaciones Periódicas de La Coordinación para La Mejora Del Personal de Educación Superior (Capes), disertaciones y tesis, que se utilizó como tema para labúsque da del Síndrome de Burnout, profesores, universidades, estrés laboral en el que se encontraron 37 producciones, en el período de 2008 a 2018. Resultados: La investigación dio como resultado 37 estudios relacionados conel Síndrome de Burnout en profesores universitarios, de loscuales 21 son tesis de maestría académica, 10 son tesis de doctorado y 06 son tesis de maestria profesional. Las tablas muestran La secuencia de producciones científicas de estudios de pos grado brasileños que se encuentran en lastesis del Portal CAPES, en referencia al tema abordado. Consideraciones finales: Huboun aumento en el número de producciones sobre el tema, siendo el área de Administración la más sensibilizada por el tema. En cuanto a la implementación educativa en la prevención de esta patología, se han observado poços estúdios con este objetivo. Se concluyó, entonces, la necesidad de elaborar investigaciones que valoren el Síndrome de Burnout como foco de intervención com el objetivo de mejorar la calidad del trabajo de los docentes y otras profesiones.

Palabras clave: Burnout, Facultad, Universidades, Estrés ocupacional.

\section{INTRODUÇÃO}

As últimas décadas têm sido sinalizadas por transformações significativas no cenário da economia, da política, social e cultural que repercutiram intensamente nas organizações e formas de trabalho. Desse modo, houve uma elevação nos casos de depressão, síndrome do pânico e de Burnout, estresse, transtornos psicóticos, mentais, relacionados ao uso de álcool etc., transtornos dos quais cada um tem maior relação com determinadas categorias profissionais (LIMA MEA, 2003).Milhões de pessoas são acometidas por algum tipo de doença mental, e a incidência desse tipo de patologia vem aumentando progressivamente. A população de trabalhadores é a mais afetada, porque grande parte dos transtornos mentais estão condicionados à rotina de trabalho (SILVA JLL, et al., 2017).

De acordo com Bertoncello B e Borges-Andrade JE (2015), as doenças mentais, como depressão, ansiedade, estresse e a Síndrome de Burnout, foram responsáveis por $9 \%$ dos afastamentos do trabalho no ano de 2014, por mais de quinze dias. No Manual de Procedimentos para os Serviços de Saúde, lançado pela Organização Pan-Americana da Saúde, no Brasil, no ano de 2001, a Síndrome de Burnout obteve destaque como condição de adoecimento mental frequente entre profissionais que trabalham no atendimento ao público, como policiais, médicos, enfermeiros, professores, entre outros. Nesse sentido, o Decreto oㅜ 3.048, de 6 de maio de 1999, o qual aprovou o Regulamento da Previdência Social, traz,no anexo II, os Agentes Patogênicos causadores de Doenças Profissionais. No item XII, da Tabela de Transtornos Mentais e do Comportamento Relacionado à Síndrome de Burnout, recebe a classificação da CID-10 com o código Z73.0 (COSTA LST, et al., 2013).

A docência tem se destacado, nos últimos anos, como sendo uma das categorias profissionais mais evidenciadas nos estudos sobre Burnout (BROUWERS A, et al., 2011). De acordo com relatos de docentes, os principais fatores que os levam ao desenvolvimento do estresse são as preocupações com o desenvolvimento acadêmico, a insatisfação com o salário, as condições de trabalho adversas, a indisciplina dos alunos, a falta de participação dos pais e a desvalorização da carreira do magistério, sem possibilidades de progredir (CARLOTTO MS e PALAZZO LS, 2006; ESTEVES-FERREIRA AA, et al., 2014).

Assim como em outros ambientes de trabalho, a Síndrome de Burnout na educação é um fenômeno complexo que resulta da interação de fatores individuais, geralmente, inicia-se com estresse laboral, progredindo gradativamente para o mal-estar que incapacita o indivíduo a desenvolver as tarefas com satisfação, posteriormente, perde-se a autoestima, evoluindo para baixos níveis de ilusão pelo trabalho, fatores estes, que contribuem efetivamente para o desgaste psíquico e a indolência. A apatia gerada pelo trabalho pode ocorrer devido a outras causas, todavia, é notório que o gatilho para o desenvolvimento da Síndrome de Burnout, na maioria das vezes, é a sobrecarga laboral (COSTA LST, et al., 2013). 
O entendimento dessa doença, complexa e multifatorial, entre os docentes, é possível a partir da investigação dos fatores potencialmente estressores presentes nos ambientes de trabalho, que fazem com que a atividade profissional seja realizada sob condições adversas à saúde física e mental dos trabalhadores (MASSA LDB, et al., 2016).

Estudo realizado no Reino Unido revelou a comparação do nível de estresse vivenciado pelos profissionais em diferentes áreas e concluiu que os professores apresentavam duas vezes mais estresse, depressão e ansiedade que a média dos outros profissionais. No Brasil, estes profissionais ocupam o segundo lugar das categorias profissionais com doenças de caráter ocupacional. Esta avaliação pode estar subestimada, pois depressão e ansiedade podem ser decorrentes do Burnout e não o diagnóstico principal (MASSA LDB, et al., 2016).

Conforme Pinotti SAG (2005/2006), em pesquisa realizada com professores da rede pública de ensino, mostrou que $92 \%$ dos professores do país apresentavam sinais de distúrbios causados pelo estresse, como dores de cabeça, ansiedade, transtornos do sono, cansaço excessivo, déficit de memória e concentração. Nesta perspectiva, professores chegam a apresentar doenças como transtornos neuróticos, depressão, hemorroida, doenças do sistema digestório, amigdalite e infecção das vias respiratórias superiores (AMADO $E, 2000)$. Mediante os dados expostos e a relevância destes para docência, este estudo vem colaborar com futuras pesquisas na área, uma vez que, segundo Esteves-Ferreira AA, et al. (2014), a produção científica relacionada à temática é pequena e recente no Brasil.

Para tanto, este estudo se propôs a realizar revisão da literatura, a qual demonstra que o pesquisador está atualizado nas últimas discussões, no campo de conhecimento em investigação. Além de verificar em artigos de periódicos nacionais e internacionais e livros publicados (PRODANOV CC e FREITAS EC, 2013). Diante disto, o estudo visou investigar a temática da Síndrome de Burnout em professores universitários, em dissertações e teses brasileiras, de 2008 a 2018.

\section{MÉTODOS}

Realizou-se um estudo de revisão integrativa da literatura, do tipo quantitativo e descritivo, sobre o tema Síndrome de Burnout, em professores universitários, utilizando-se do Portal de Periódicos da Coordenação de Aperfeiçoamento de Pessoal de Nível Superior (Capes). A coleta de dados foi realizada em novembro de 2018, através do Banco de Teses e Dissertações da CAPES, por meio dos termos "Síndrome de Burnout" e "Professores Universitários", utilizando o operador booleano AND; e o próprio título do presente artigo "Síndrome de Burnout em professores universitários".

Como critério de inclusão, foram considerados resumos referentes à Síndrome de Burnout em professores universitários, publicados no período de 2008 a 2018, na língua portuguesa. Foram excluídos, estudos que se reportavam a Síndrome de Burnout em professores de ensino médio e /ou fundamental. Por fim, após seleção, foram obtidos 37 artigos (Figura 1).

As variáveis elencadas foram: ano de produção, região brasileira da instituição que produziu a dissertação/tese, nível, área do conhecimento, assunto abordado, finalidade educativa. Os resultados foram organizados em números absolutos e apresentados em tabelas. $\mathrm{Na}$ análise, verificou-se abordagem dos pesquisadores no âmbito da convergência e/ou divergência dos achados. Para tanto, foram percorridos alguns caminhos para a realização da busca da pesquisa, conforme descrito no fluxograma abaixo: 
Figura 1 - Fluxograma com os caminhos percorridos para a realização da busca dos estudos.

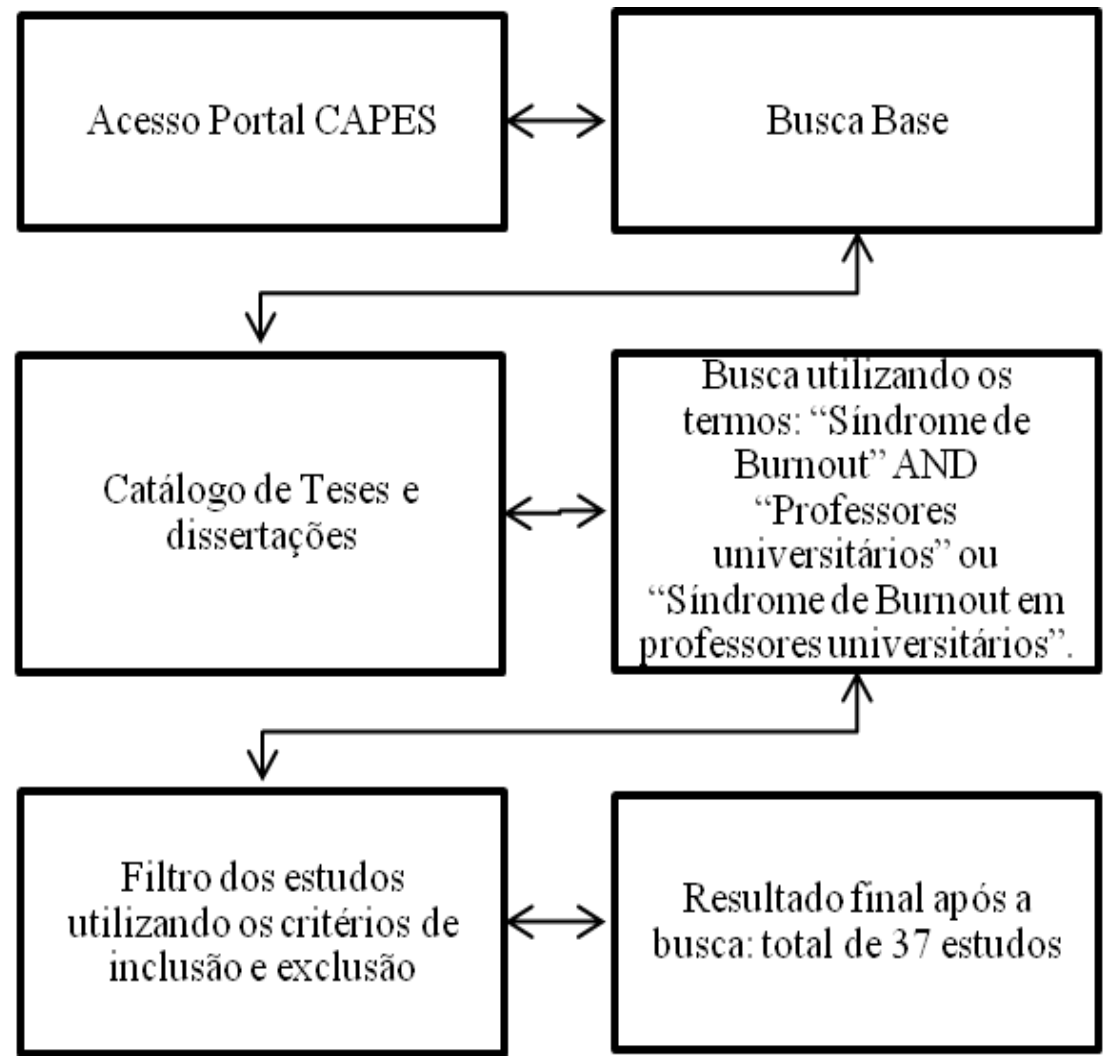

Fonte: Oliveira MTB, et al., 2020; dados extraídos do Portal CAPES.

\section{RESULTADOS}

A pesquisa resultou em 37 estudos relacionados à Síndrome de Burnout em professores universitários, dos quais 21 são dissertações de mestrado acadêmico, 10 são teses de doutorado e 06 são dissertações de mestrado profissional. As tabelas mostram sequência das produções científicas da pós-graduação brasileira encontradas no Portal CAPES teses, referente ao tema abordado.

Na Tabela 1, observam-se os anos de publicação das dissertações e teses, de acordo com o intervalo de ano, correlacionando com a região brasileira. Constatou-se que a Região Sudeste foi a que produziu mais (17) seguida da Sul (8). O período em que mais houve publicação foi entre 2016 e 2017.

Tabela 1 - Ano de publicação das teses e dissertações, conforme a região brasileira. Palmas -TO, 2018.

\begin{tabular}{|c|c|c|c|c|c|c|}
\hline & & Regiões & Brasileiras & & & \\
\hline Período & Centro Oeste & Norte & Nordeste & Sudeste & Sul & Total \\
\hline $2008-2009$ & 1 & 2 & 0 & 4 & 0 & 7 \\
\hline $2010-2011$ & 0 & 0 & 1 & 3 & 0 & 4 \\
\hline $2012-2013$ & 0 & 1 & 2 & 2 & 1 & 6 \\
\hline $2014-2015$ & 0 & 0 & 0 & 4 & 2 & 6 \\
\hline 2016-2017 & 0 & 0 & 4 & 4 & 3 & 11 \\
\hline 2018 & 0 & 1 & 0 & 0 & 2 & 3 \\
\hline
\end{tabular}

Fonte: Oliveira MTB, et al., 2020. Dados extraídos do Portal CAPES.

A Tabela 2 destaca o nível de pós-graduação pela área de conhecimento reunido, de acordo com a classificação da CAPES. A área da Administração (7), seguida da Psicologia (6) e Educação (4), foram as que mais realizaram pesquisas na pós-graduação sobre Síndrome de Burnout em professores universitários. 
Tabela 2 - Níveis de pós-graduação por área do conhecimento. Palmas - TO, 2018. Níveis de pós-graduação por área do conhecimento. Palmas - TO, 2018.
Área do Conhecimento

\begin{tabular}{lcccc}
\hline & Mestrado & Doutorado & Mestrado Profissional & Total \\
\hline Administração & 3 & 1 & 3 & 7 \\
\hline Psicologia & 6 & 0 & 0 & 6 \\
\hline Educação & 3 & 1 & 0 & 4 \\
\hline Promoção da Saúde & 1 & 0 & 0 & 1 \\
\hline Psicologia Clínica & 1 & 0 & 0 & 1 \\
\hline Ensino na Saúde & 1 & 0 & 0 & 1 \\
\hline Psicologia Educacional & 1 & 0 & 0 & 1 \\
\hline Enfermagem & 0 & 1 & 0 & 1 \\
\hline Psicologia do Desenvolvimento e & 1 & 0 & 0 & 1 \\
Aprendizagem & 1 & 0 & 0 & 2 \\
\hline Medicina & 0 & 2 & 1 & 1 \\
\hline Ensino de Ciências da Saúde & 0 & 0 & 0 & 1 \\
\hline Políticas Públicas e formação humana & 0 & 1 & 0 & 2 \\
\hline Odontologia & 0 & 2 & 1 & 1 \\
\hline Ensino em Saúde & 0 & 0 & 0 & 1 \\
\hline Desenvolvimento Regional & 1 & 0 & 0 & 1 \\
\hline Saúde Coletiva & 1 & 0 & 1 & 1 \\
\hline Ensino de Ciências na Amazônia & 0 & 0 & 0 & 1 \\
\hline Educação Física & 1 & 0 & 0 & 2 \\
\hline Enfermagem Psiquiátrica & 1 & 1 & 0 & 1 \\
\hline Medicina e Saúde & 0 & 1 & 6 & 37 \\
\hline Total & 21 & 10 & & \\
\hline Eote: Olvera MTB, et al. & 0 & 0 & 1 \\
\hline
\end{tabular}

Fonte: Oliveira MTB, et al., 2020. Dados extraídos do Portal CAPES.

A Tabela 3 é referente ao nível da literatura dos assuntos investigados, conforme a ideia principal que o resumo evidenciava. Deste modo, observa-se que a Avaliação/análise foi a que mais se destacou, com 17 produções. Na Tabela 4 destaca a produção científica relacionada ao propósito educativo, em que se observa que na maioria das produções (21) não havia finalidade educativa notória.

Tabela 3 - Nível da literatura dos assuntos investigados. Palmas - TO, 2018.

\begin{tabular}{lcccc}
\hline \multicolumn{1}{c}{ Assunto } & Mestrado Acadêl da Literatura & & \\
\hline Avaliação/Análise & 9 & Mestrado Profissional & Doutorado & Total \\
Intervenção & 0 & 0 & 5 & 17 \\
Exposição/Descrição & 5 & 2 & 1 & 1 \\
Conhecimento/Diagnóstico & 8 & 1 & 2 & 9 \\
\hline Total & 22 & 6 & 1 & 10 \\
\hline
\end{tabular}

Fonte: Oliveira MTB, et al., 2020. Dados extraídos do Portal CAPES.

Tabela 4 - Produção científica relacionada ao propósito educativo. Palmas - TO, 2018.

\begin{tabular}{ccccc}
\hline \multicolumn{5}{c}{ Nível da Literatura } \\
\hline Propósito Educativo & Mestrado Acadêmico & Mestrado Profissional & Doutorado & Total \\
\hline Sim & 8 & 3 & 5 & 16 \\
Não & 14 & 3 & 4 & 21 \\
\hline Total & 22 & 6 & 9 & 37 \\
\hline
\end{tabular}

Fonte: Oliveira MTB, et al., 2020. Dados extraídos do Portal CAPES.

\section{DISCUSSÃO}

A Tabela 1 demonstra que entre 2008 a 2015 a produção científica relacionada à temática não ocorria de forma expressiva. Contudo, entre os anos de 2016 a 2017 houve um aumento significativo das produções científicas referentes à Síndrome de Burnout (SB) em professores universitários, reforçando a relevância de estudar o assunto e torná-lo em evidência para comunidade científica e sociedade. 
Durante este período de acedência das produções, Prado RL, et al (2017), realizaram um estudo, que evidenciou a possibilidade da SB está em processo nos professores universitários, foi estudado as três dimensões de Burnout: Exaustão Emocional (EE), Despersonalização (DP) e Eficácia Profissional (EP), onde a dimensão EE se destacou com a maior pontuação média $(1,80)$, que de acordo com os autores Carlotto MS e Palazzo LS (2006), Maslach C (2001), a dimensão EE é a precursora no processo de evolução da síndrome, acompanhada pela dimensão DP e EP. Resultados semelhantes também foram encontrados por Silva SMF e Oliveira AF (2019), em que a exaustão se destaca das demais dimensões, nos professores identificados com SB. Para Boujut E, et al. (2016), a exaustão emocional é um atributo principal da SB, é considerada critério importante para diagnóstico diferencial, entretanto, não é suficiente. Por este motivo, há a necessidade da presença de pelo menos uma das outras duas dimensões para poder caracterizar a SB.

Nessa perspectiva, é possível afirmar que a Síndrome de Burnout pode afetar a qualidade de vida desses profissionais, na proporção em que o trabalho é uma das funções que perpassa pela existência humana e faz parte da distinção de como o indivíduo se discerni no mundo. Deste modo, os impactos da (SB) não se limitam ao contexto laboral, expandindo-se para questões de realização pessoal e impactando no planejamento existencial do indivíduo (CASTRO FG, 2013). Desse modo, a pessoa que somatiza os seus problemas tanto no âmbito profissional quanto pessoal, pode apresentar uma exaustão física e emocional, que pode evoluir para SB, que de acordo com Jesus LMS, et al. (2017), é a resposta do estresse crônico, apresentando sintomas, como cefaleia intensa, dispneia, alteração de humor, dificuldade de concentração, problemas digestivos e outros.

Estudos realizados nos Estados Unidos na década de 1980 apontavam o surgimento significativo da Síndrome de Burnout em professores. No Brasil, as pesquisas são consideradas recentes, porém expressivas. O Burnout faz parte da realidade da rotina de professores brasileiros. Portanto, compreendê-lo, identificá-lo e combatê-lo deve ser preocupação daqueles que buscam a melhoria do processo educativo (BARBOSA ALKH, 2016; BARBOSA I, 2014).

Nesse sentido, Lima MFEM e Lima Filho DO (2009), identificaram a associação entre o processo de trabalho e o provável adoecimento físico e mental em professores de uma universidade pública. Os resultados apontam que os docentes exibem desgaste psicológico, exaustão emocional, entre outros sintomas. Estes resultados levam a uma reflexão sobre o processo de trabalho destes profissionais nas instituições públicas de ensino superior brasileiras, a forma como estão expostos a situações e fatores desencadeantes que interferem diretamente na saúde física, psíquica, bem como, social

Contudo, a prevalência do problema ao redor do mundo ainda é considerada incerta. Entretanto, no ranking de oito países classificados pela International Stress Management Association do Brasil (ISMA-BR), o Brasil está à frente da China e dos Estados Unidos, perdendo apenas para o Japão, em que $70 \%$ da população apresenta os sintomas do Burnout (MONTEIRO L, 2019).

Recentemente, a Organização Mundial da Saúde (OMS) redefiniu a SB ou esgotamento profissional, a qual foi oficializada como resultado de "estresse crônico de trabalho que não foi administrado com sucesso". Segundo pesquisa realizada pelo ISMA-BR, em $2018,72 \%$ da população brasileira sofreu alguma sequela do estresse, do leve ao devastador, dentre os quais, 32\% teve a Síndrome de Burnout (GRANATO L, 2019).

Baptista MN, et al. (2019), verificaram que a SB tem ligação relevante e positiva com eventos estressores no trabalho e depressão, evidenciando que 0 aumento do estresse no trabalho e sintomas depressivos corroboram com a sintomatologia referente à SB. Foi evidenciado também, que a falta de suporte laboral, ou o suporte ineficiente reflete de forma negativa na saúde do profissional e contribui para 0 surgimento de fatores estressores que podem desencadear a SB.

Nessa perspectiva, torna-se importante entendermos como se desenvolve o processo de desencadeamento dessa doença para poder nortear estratégias de prevenção. Sendo assim, a SB é constituída por quatro aspectos relevantes: ilusão pelo trabalho, definido como a compreensão de que o trabalho promove desafios, e o alcance de metas profissionais é um estado de realização pessoal; 2) 
desgaste psíquico, denotado pelo sentimento de cansaço físico e emocional em ter de lidar, diariamente, no trabalho, com fatores estressantes e pessoas que apresentam algum tipo de problema; 3 ) indolência, entendida como a presença de atitudes negativas de indiferença, insensibilidade e distanciamento frente aos clientes, colegas e organização; 4) culpa, determinada pelo aparecimento de sentimentos de culpabilização por atitudes e comportamentos não compatível com as normas internas e cobrança social acerca do papel profissional (CARLOTTO MS, et al., 2015).

Nesse sentido, pode ser desencadeado a Síndrome de Burnout (SB), a qual é entendida como resposta ao estresse laboral crônico, característica dos profissionais que trabalham diretamente com o público, apresentando, ainda, exaustão emocional/física, frustração profissional, despersonalização e diminuição da realização profissional (ESTEVES-FERREIRA AA, et al., 2014; CARLOTTO LM, et al., 2015; MOREIRA DL, et al., 2016; MASSA LDB, et al., 2016).

A Região Sudeste obteve o maior número de produção, seguida da Sul, fato que pode ser justificado, provavelmente, pelo maior número de instituições de ensino e pesquisa que ambas as regiões possuem, o que favorece o desenvolvimento e a realização de maior número de pesquisas científicas realizadas.

Na Tabela 2, constatou-se maior produção na pós-graduação relacionado ao mestrado acadêmico (21), sendo a Administração a área que mais se destacou, seguida da Psicologia e Educação. Ao partir para reflexão voltada para área administrativa, observa-se que as modificações ocorridas no cenário mundial relacionadas ao trabalho, diante da globalização, têm exigido mudança de comportamento e perfil dos trabalhadores, de modo que estes precisam se adaptar às inovações tecnológicas introduzidas nos processos produtivos.

Com isso, surge à necessidade da construção de nova concepção de trabalho, resultado do aumento do ritmo, da complexidade das tarefas e das responsabilidades exigidas, reduzindo, deste modo, o número de empregos e ampliando, consequentemente, o trabalho precário, implicando transformações nos processos de trabalho e na relação saúde-doença (SOUSA JC, 2017; ANDRADE PS e CARDOSO TAO, 2012).

A Organização Internacional do Trabalho (OIT, 2012) aponta que o estresse ocupacional é, na atualidade, uma das mais importantes questões de saúde mundial e tem sido alvo de preocupação em muitos países e nos mais diferentes contextos de trabalho.

Tal preocupação se deve ao impacto negativo que causa na saúde física e mental dos trabalhadores, assim, elevando os altos índices de afastamento laboral, com evidente diminuição da produtividade nas organizações de trabalho (CARLOTTO MS, et al., 2015).

A OIT sugere que, atualmente, um em cada 10 trabalhadores sofram de estresse crônico, Síndrome de Burnout, depressão ou ansiedade, e que essas manifestações conduzem ao desemprego, aumento do índice de desalentos, gerando ambiente propício para o surgimento de outras patologias de sintomatologia física: arritmias cardíacas, insônia, falta de ar, perda de memória, pressão alta, sentimento de culpa intensa e humor imprevisível. Isso pode ser explicado fisiologicamente pelo aumento dos índices de cortisol e adrenalina livres no sangue, em períodos longos de estresse excessivo (MOLERO PP, et al., 2018).

Mediante esses fatores, vários problemas de saúde surgem como consequências a Síndrome de Burnout que, nas últimas décadas, tem despertado atenção de pesquisadores, profissionais especializados e das categorias ocupacionais mais vulneráveis em todo o mundo (SCHAUFELI WB, et al., 2009). Observase nos dados da Tabela 3 que os assuntos explorados, em maioria no mestrado, estavam relacionados a avaliar e analisar a percepção de docentes a respeito da SB, seguido do conhecimento e diagnóstico relacionados aos fatores desencadeadores do Burnout. Pesquisas em diferentes culturas indicam que professores estão entre os profissionais que apresentam maiores níveis de estresse no trabalho, sendo uma das atividades ocupacionais mais expostas à ambientes conflituosos e à alta exigência de trabalho (CARLOTTO MS, et al., 2015).

Para Costa LST, et al. (2013), a Síndrome de Burnout deve ser tratada como questão de saúde pública. $\mathrm{Na}$ educação, é considerada epidemia e uma das cinco causas mais comuns de afastamento do trabalho. 
Geralmente, o professor pede afastamento por queixas de sintomas físicos que o impossibilitam de exercer as atividades laborais.

O diagnóstico é feito por médico perito que deve ter, além do conhecimento técnico, entendimento das leis, normas e portarias. Pois, esse domínio da legislação trabalhista implicará manutenção dos direitos ao profissional afastado, que se the forem negados alguns benefícios, pode implicar agravamento do quadro clínico, decorrente de fatores emocionais. Nesse sentido, observa-se que SB implica necessidade de reflexão a respeito de medidas de avaliação que visem prevenção, promoção da saúde e controle dos fatores desencadeantes, uma vez que atinge diretamente a saúde física e mental desses profissionais.

De acordo com a Tabela 4, este estudo evidenciou propósito educativo na produção científica, que seriam discussões, diálogos, debates sobre a temática Síndrome de Burnout, publicações científicas sobre o assunto para subsidiar a comunidade acadêmica, estimulando o desenvolvimento de futuras pesquisas. No entanto, pôde-se perceber que o maior número foi de produções sem esse propósito. A maioria das produções ficou apenas nos repositórios das instituições de ensino.

Logo, precisam ser incentivados estudos que tenham como alicerce informar o indivíduo e a comunidade sobre a SB, pois está presente na maioria dos profissionais que lidam diretamente com o público, não sendo restrita apenas à docência. Na experiência da docência, é preciso ser reencontrada a crítica à racionalidade instrumental e disciplinar, para lidar com as situações adversas que o professor vive no ambiente de trabalho, buscando trabalhar os fatores determinantes e desencadeadores do Burnout.

Frequentemente, alguns indivíduos acabam se envolvendo cada vez mais com a rotina de atividades laborais, que acabam desenvolvendo afetividade pelo trabalho que pode ser positiva ou negativa. Quando o resultado é negativo, esses indivíduos podem desenvolver problemas de saúde, como estresse e ansiedade, provocado pelo estado psicológico desestruturado por causa do trabalho excessivo e da incessante busca pelo sucesso (MOREIRA DL, et al., 2016).

Diante do exposto, observa-se a necessidade de trabalhar a SB nos diversos ambientes de trabalho, sobretudo, dos docentes, à medida que estes profissionais estão vulneráveis a circunstâncias condicionantes que desencadeiam a doença. É importante desenvolver medidas que previnam o desencadeamento dos fatores, desenvolvendo ações educativas e preventivas que trabalhem saúde física, mental e emocional, visando minimizar situações estressoras de modo que obtenham uma melhor qualidade de vida e desempenho profissional.

\section{CONSIDERAÇÕES FINAIS}

Constatou-se um crescimento do número de produções relacionadas a essa temática, onde a maior proporção foi no mestrado acadêmico, com propósito de avaliar e analisar a dinâmica da SB na docência. Poucos estudos obtiveram a finalidade de implementação educativa, demonstrando a necessidade de elaborar pesquisas que ressaltem a gravidade e nocividade da SB a nível individual, organizacional e social. As ações educativas voltadas para prevenção dessa doença são escassas, refletindo a importância e urgência de se diagnosticar a síndrome o mais precoce possível.

Portanto, espera-se que este estudo possa subsidiar novas pesquisas na área e ampliar a reflexão acerca do tema, corroborando para criação de políticas públicas que visem a melhoria da qualidade do trabalho de docentes e demais profissões.

\section{REFERÊNCIAS}

1. ANDRADE OS, CARDOSO TAO. Prazer e dor na docência: revisão bibliográfica sobre a síndrome de Burnout. Saúde e Sociedade, São Paulo, 2012; 21 [1]: 129-140.

2. AMADO E. O trabalho dos professores do ensino fundamental: uma abordagem ergonômica. Dissertação (Mestrado em Engenharia de Produção) - Universidade Federal de Santa Catarina, Florianópolis, 2000; 104 p.

3. BARDIN L. Análise de Conteúdo. Edição Revista e Atualizada, 70ª̣ ed, Lisboa-Portugal, 2010. 
4. BARBOSA ALKH. A Síndrome de Burnout em professores universitários. Dissertação (mestrado) - Centro Universitário de Maringá, Programa de Pós-Graduação em Promoção da Saúde, Maringá, 2016, 98 p.

5. BARBOSA I. O Burnout e suas Implicações no Ensino de Ciências. Revista Areté: Revista Amazônica de Ensino de Ciências, 2014;1[1]: 33-43.

6. BATISTA JBV, et al. Síndrome de Burnout: confronto entre o conhecimento médico e a realidade das fichas médicas.Revista Psicologia em estudo, 2011;16 [3] : 429-435.

7. BAPTISTA MN, et al. Burnout, estresse, depressão e suporte laboral em professores universitários. Revista Psicologia: Organizações e Trabalho, 2019; 19 [1]: 564-570.

8. BERNARDO MLD, et al. Síndrome de Burnout em professores universitários. Rev Ter. Ocup Univ., $2016 ; 27$ [2] : $180-9$.

9. BERTONCELLO B, BORGES-ANDRADE JE. Relações entre Saúde Mental do Trabalhador e Suporte Organizacional. Revista Laborativa, 2015; 4[ 2]: 85-102.

10. BOUJUT E, et al. Comparative study of teachers in regular schools and teachers in specialized schools in France, working with students with an autism spectrum disorder: stress, social support, coping strategies and burnout. Journal of Autism and Developmental Disorders, 2016; 46(9): 2874- 2889.

11. BROUWERS A, et al. Job demands, job control, social support and self- efficacy beliefs as determinants of Burnout among physical education teachers. Europe's Journal of Psychology, 2011; 1 [sn] :17-39.

12. CARLOTTO MS, et al. O papel mediador da autoeficácia na relação entre a sobrecarga de trabalho e as dimensões de Burnout em professores. Psico - USF, 2015; 20 [1]: 13-23.

13. CARLOTTO MS, PALAZZO LS. Síndrome de Burnout e fatores associados: um estudo epidemiológico com professores. Cad Saúde Pública, 2006; 22 [5]: 1017-106.

14. CASTRO FG. Burnout e Complexidade Histórica. Revista Psicologia: Organização e Trabalho, $2013 ; 13$ [1]: 49 60.

15. CHIAPETTI RJN. Pesquisa de campo qualitativa: uma vivência em geografia humanista. Geotextos, $2010 ; 6$ [2]:139-162.

16. COSTA LST, et al. Prevalência da Síndrome de Burnout em uma amostra de professores Universitários brasileiros.Psicologia: reflexão e Crítica, 2013; 26 [4] : 636-642.

17. CRACCO CLAC, SALVADOR JA. Identificação da síndrome de Burnout na equipe de enfermagem de uma unidade de pronto atendimento. Trabalho de Conclusão de Curso (Graduação em Enfermagem) Centro Universitário Católico Salesiano Auxilium, UNISALESIANO, São Paulo, 2010, 59 p.

18. DALAGASPERINA P, MONTEIRO JK. Preditores da síndrome de Burnout em docentes do ensino privado. Psico USF, 2014;19 [2]: 263-275.

19. ESTEVES-FERREIRA AA, et al. Avaliação comparativa da Síndrome de Burnout em professores de escolas públicas e privadas. Revista Brasileira de Educação, 2014; 19 [59]: 987-1002.

20. GRANATO L. O que significa a mudança da OMS sobre a Síndrome de Burnout? Exame. 2019.

21. JESUS LMS, et al. ASPECTOS DESENCADEANTES DA SÍNDROME DE BURNOUT EM ENFERMEIROS DA ESTRATÉGIA SAÚDE DA FAMÍLIA. International Journal of Development Research, 2017; 9 [11]:16529-16533.

22. JODAS DA, HADDAD MCL. Síndrome de Burnout em trabalhadores de enfermagem de um pronto socorro de hospital universitário, 2018.

23. LIMA MEA. A polêmica em torno do nexo causal entre distúrbio mental e trabalho. Psicologia em Revista, 2003;10[14]: 82-91.

24. LIMA MFEM, LIMA-FILHO DO. Condições de trabalho e saúde do/a professor/a universitário/a. Ciências \& Cognição, 2009; 14[3]: 62-82.

25. MASSA LDB, et al. Síndrome de Burnout em professores universitários. Rev Ter Ocup Univ São Paulo, 2016 ; 27 [2]: 180-9.

26. MASLACH C, et al. JobBurnout. Annual review of psychology, 2001; 52 [1]:397-422.

27. MOLERO PP, et al. An Explanatory Model of Emotional Intelligence and Its Association with Stress, Burnout Syndrome, and Non-Verbal Communication in the University Teachers.Clin Med., 2018;7 [12]: 524.

28. MOREIRA DL, et al. Síndrome de Burnout: estudo com professores da rede pública da cidade de Farroupilha no Rio Grande do Sul. Proceeding of ISTI/SIMTEC. 2016; 3 [1]: 090-098, Aracaju/SE - VII International Symposium on Technological Innovation. Innovation to Inspire and Implement.

29. MONTEIRO L. OMS classifica a síndrome de Burnout como doença. Super Interessante. Disponivel em: <https://super.abril.com.br/saude/oms-classifica-a-sindrome-de-Burnout-como-doenca/>. Acesso em: 31 maio 2019.

30. PEDRO N, PEIXOTO F (2016). Satisfação profissional e autoestima em professores do $2^{\circ}$ e $3^{\circ}$ ciclos do ensino básico. In: SOUZA, S. et al. Síndrome de Burnout e valores humanos em professores da rede pública estadual da cidade de João Pessoa. Análise Psicológica. 1, XXXIV,2016,119-131.

31. PÊGO FPL, PÊGO DR . Síndrome do Burnout. Revista Bras Med Trab., 2016; 14 [2]:171-176. 
32. PINOTTI SAG. Stress no professor: fontes, sintomas e estratégias de controle. Revista Uniara, Araraquara: Centro Universitário de Araraquara, 2005/2006; 9 [2]: 207 - 216.

33. PRADO RL, et al. Avaliação da síndrome de Burnout em professores universitários. Revista da ABENO, 2017; 17 [3]: $21-29$.

34. PRODANOV CC, FREITAS EC. Metodologia do trabalho científico [recurso eletrônico]: métodos e técnicas da pesquisa e do trabalho acadêmico. 2. Ed., 2013.

35. SILVA JLL, et al. Prevalência de transtornos mentais comuns entre trabalhadores marítimos do Rio de Janeiro. Rev Fund Care Online., 2017; 9 [3]:676-681.

36. SOUSA JC. Relação entre Síndrome de Burnout e resiliência na atividade docente superior [recurso eletrônico]. Dissertação de mestrado (mestrado acadêmico). Universidade Federal do Ceará, Centro de Estudos Sociais Aplicadas, Mestrado Acadêmico em Administração, Fortaleza.2017, 128 p.

37. SCHAUFELI WB, et al. Síndrome de Burnout: 35 years of research and practice. Career Development International, 2009; 14 [3]: 204-220.

38. SEVERINO AJ. Metodologia do Trabalho Científico. 23ํe ed. São Paulo, 2013.

39. SILVA SMF, OLIVEIRA AF. Burnout em professores universitários do ensino particular. Psicologia Escolar e Educacional, 2019; 23: e187785.

40. SOUZA S, et al. Síndrome de Burnout e valores humanos em professores da rede pública estadual da cidade de João Pessoa. Análise Psicológica. 1, 2016; 34 [2]: 119-131. 